Published in final edited form as:

Pediatr Obes. 2016 February ; 11(1): 47-53. doi:10.1111/ijpo.12019.

\title{
10-year beverage intake trends among U.S. preschool children: Rapid declines between 2003 and 2010, but stagnancy in recent years
}

\author{
Christopher N. Ford, \\ Department of Nutrition, University of North Carolina at Chapel Hill \\ Shu Wen $\mathrm{Ng}$, and \\ Department of Nutrition, University of North Carolina at Chapel Hill \\ Barry M. Popkin \\ Department of Nutrition, University of North Carolina at Chapel Hill
}

\begin{abstract}
Background-It has been previously reported that total energy intake among U.S. preschool children (ages 2-5y) decreased between 2003-04 and 2009-10. However, little is known about how intakes of beverages among U.S. preschoolers (ages 2-5y) changed from 2003-04 through 2011-12. This paper examines changes in intakes of key beverages during this period, as well as how eating location (at home or away from home) and source (store vs others) may have contributed to these changes.
\end{abstract}

Methods-Cross-sectional day one dietary data among children ages 2-5y from the National Health and Nutrition Examination Survey (NHANES) 2003-04, 2005-06, 2007-08, 2009-10 and 2011-12 were used. Survey-weighted mean intakes by survey year, eating location, and source, were computed for total sugar sweetened beverages (SSBs), milks, 100\% juice, low/no-calorie beverages, 10 key beverages, total beverages and total foods. Means were compared using twotailed $z$-tests with Bonferroni corrections $(a<0.05)$.

Results-Between 2003-04 and 2011-12, among 2-5 year olds, total caloric intake fell by 132 $\mathrm{kcal} / \mathrm{d}$, with intakes of beverages falling by $55 \mathrm{kcal} / \mathrm{d}$. Decreases in intakes of total SSBs $(-57$ $\mathrm{kcal} / \mathrm{d}$ ), fruit-flavored or juice drinks containing $<100 \%$ juice (juice drinks) $(-37 \mathrm{kcal} / \mathrm{d})$, caloric soft drinks $(-13 \mathrm{kcal} / \mathrm{d})$, and $>1 \%$ fat, low-sugar milk $(-42 \mathrm{kcal} / \mathrm{d})$ were among the major changes. By eating location, total beverage intake at home fell by $73 \mathrm{kcal} / \mathrm{d}$. By source, total beverage intake from stores fell by $106 \mathrm{kcal} / \mathrm{d}$. Changes in intakes occurred primarily between 2003-04 and 2009-10, as there were no significant differences in beverage intakes between 2009-10 and 201112. Intakes of total calories $(+49 \mathrm{kcal} / \mathrm{d})$, and calories from foods $(+53 \mathrm{kcal} / \mathrm{d})$, trended upward between 2009-10 and 2011-12, but changes were not significant.

Corresponding author address: Barry Popkin, Carolina Population Center, CB \# 8120 University Square, University of North Carolina at Chapel Hill, Chapel Hill, NC 27516-3997, popkin@unc.edu.

None of the authors have any conflict of interests of any type with respect to this manuscript. 
Conclusions-These findings suggest improvements in the diets of preschoolers between 200304 and 2009-10, of which stores were a major contributor.

\section{Keywords}

Sugar-sweetened beverages; preschool child; dietary trends

\section{Introduction}

Beverages such as sugar-sweetened beverages (SSBs) and whole-fat milks are leading sources of added sugars and solid fats, respectively, in the diets of U.S. children (1), and contribute nearly one fifth of total caloric intake (2). Thought to have a smaller relative effect on satiety than foods $(3,4)$, beverages may promote overeating by making it difficult to adjust food intake as caloric needs are met (5). Thus, over-consuming calories from beverages can lead to excess weight gain (6), which is why beverages are the focus of a number of U.S. child obesity prevention initiatives (7-9). For promoting healthy beverage habits, preschool children (ages 2-5y) are an important population, as this stage encompasses the development of dietary behaviors that may track into later life stages (10).

While earlier studies have found total energy intake among U.S. preschoolers fell by 178 kcal between 2003-04 and 2009-10 (1), little is known of how intakes of beverages such as low-fat, low-sugar milk; $100 \%$ fruit juice; and caloric soft drinks may have contributed to this trend. A recent study showed decreases in intakes of SSBs and whole-fat milks, along with increases in intakes of low-fat milk between 2001-02 and 2009-10 (11). However, age group-specific findings were not reported. Slining and Popkin (2013) noted intake of total milks among U.S. preschoolers declined between 2003 and 2010. Yet, changes in intakes of major milk subgroups over this period are unclear, as milks were combined into a single category. The 2010 U.S. Dietary Guidelines for Americans distinguishes milks containing $1 \%$ or less fat by volume (low-fat) from those containing more than $1 \%$ fat ( $2 \%$ and wholefat milks) (12). High- and low-fat milks can be further sub-grouped into high- ( $22 \mathrm{~g}$ sugar per $8 \mathrm{oz}$ serving) and low-sugar varieties ( $<22 \mathrm{~g}$ sugar per $8 \mathrm{oz}$ serving) (13). To determine how intakes of these subcategories of milk may have shifted since 2003 among U.S. preschoolers, further study is needed. Recent changes in the Special Supplemental Nutrition Program for Women, Infants and Children (WIC), in particular, give cause to investigate these important milk subgroups. In 2009, WIC replaced whole milk with milks containing $\mathcal{s} \%$ fat content in packages for children ages two and older (14).

Similarly, there is cause for further investigation on trends in intakes of SSBs among U.S. preschoolers since 2003. Healthy People, directed by the U.S. Department of Health and Human Services, aims to improve the health of the U.S. population by setting goals every ten years to direct major public health initiatives. Reducing consumption of calories from added sugars among individuals ages two and older was an objective in Healthy People 2020 (15). SSBs are known to be a leading source of added sugars in the diets of U.S. preschoolers (16), and taxing these beverages has been a central controversy in the childhood obesity prevention discourse (17). Yet, while a 2013 study found total intake of SSBs among U.S. preschoolers also declined between 2003 and 2010 (18), intakes of key 
sugared beverages such as caloric soft drinks, juice drinks, and sport and energy drinks, were not reported separately, making it unclear how intakes of these beverages among U.S. preschoolers changed over this period.

By source (where the food/beverage is purchased/obtained), preschool children consume more calories from stores than from all other sources combined, and the majority of these foods/beverages are consumed at home (19). Despite the significance of these food/beverage intake domains, there have been no studies to examine how beverage intake by eating location (at home or away from home) and source have changed since 2003. Moreover, as several major retailers and food manufacturers pledged to make healthier products and sell fewer calories during this period (20), there is particular cause to investigate trends in preschooler beverage intakes from stores.

To address these important gaps, we used the What We Eat in America dietary intake data from the National Health and Nutrition Examination Survey (NHANES) 2003-2004; 20052006; 2002-2008; 2009-2010; and 2011-2012. We aimed first to determine whether there were significant changes in intakes of total calories, total beverages, total milks, SSBs, $100 \%$ fruit juice, and low/no-calorie beverages among U.S. preschool children between 2003 and 2012. Next, we sought to characterize trends in intakes of important beverages comprising these larger groups. Lastly, we looked at how eating location (at home or away from home) and source (stores, dine-in restaurants, fast food restaurants, school cafeteria or child care center, and all other sources) contributed to changes in intakes of these beverages over time.

\section{Methods}

\section{Data and subjects}

We used data from NHANES, a survey of foods consumed by the U.S. population administered jointly by the U.S. Department of Health and Human Services and the U.S. Department of Agriculture (USDA). NHANES uses a complex multi-stage sampling design in order to optimally reflect the demographic composition of the U.S. population during each 2-year survey cycle (21). Diet is ascertained using interviewer-administered 24-hour dietary recall surveys and a 5-step automated multiple pass procedure to enhance the accuracy of reported data (22). Parents/caregivers, who completed dietary recall interviews by proxy for children younger than six, were asked to report whether foods/beverages were consumed at or away from home, as well as the source of each food reported. Respondents could select from 22 possible food/beverage sources, which we grouped into the following larger categories: 1) stores; 2) dine-in restaurants; 3) fast-food restaurants; 4) school cafeterias or child care centers; and 5) all other sources.

Nutrition facts for dietary data are derived using the USDA Food and Nutrient Database for Dietary Studies (FNDDS). Demographic and dietary intake data were included for children ages 2-5 years who participated in NHANES during survey years 2003-04, 2005-06, 2007$08,2009-10$, and 2011-12. These survey years were selected in order to examine a 10-year period, during which NHANES surveys used consistent methodology (21). Our focus on this 10-year period was also motivated by the apparent shift in the trend of U.S. child obesity 
that occurred between 2003-04 and 2011-12 (23). Five versions of the FNDDS were used: version 2.0 was applied to NHANES 2003-2004; version 3.0 was applied to NHANES 2005-2006; version 4.1 was applied to NHANES 2007-2008; version 5.0 was applied to NHANES 2009-2010, and FNDDS 2011-2012 was applied NHANES 2011-2012. Per person beverage intake was computed using data from a single 24-hour recall collected on the first of two days of recall.

\section{Food grouping system}

Beverages consumed by respondents were partitioned into categories with the goal of creating beverage groups with public health significance (24). Thus, we sought to separate total milks by fat and sugar content, disaggregate sugar-sweetened beverages into important subgroups, and to discern $100 \%$ fruit juice from juice-containing drinks consisting of less than $100 \%$ juice. NHANES foods/beverages are characterized by a USDA food code, corresponding food description, and nutrient profile. Using these data, we created six major beverage groups: 1) total beverages; 2) total milks; 3) SSBs; 4) 100\% fruit juice; 5) low/nocalorie beverages; and 6) all other beverages. The intake of total milks was computed by summing intakes of all USDA food codes corresponding to liquid milks, then further separating them into four categories using nutrient values from FNDDS and sugar and fat content guidelines specified by the Institute of Medicine (24). Milks containing $\geq 22$ grams of sugar per 8-ounce serving were classified as 'high-sugar', while milks containing $₫ \%$ fat by volume were classified as 'low-fat', resulting in a total of four groups: 1) low-fat, lowsugar milk; 2) low-fat, high-sugar milk; 3) >1\% fat, low-sugar milk; and 4) >1\% fat, highsugar milk. 'Sugar-sweetened beverages' is commonly used in the literature to refer to juice drinks (fruit flavored and/or juice-containing beverages comprising < $100 \%$ fruit juice), caloric soft drinks, and sport and energy drinks $(25,26)$. Accordingly, SSBs were subdivided into juice drinks, caloric soft drinks, and sport and energy drinks. We also created a fourth SSB subcategory, other SSBs, to capture less commonly consumed (by young children) SSBs such as sweetened teas, coffees, and hot chocolate, sweetened soymilks, horchata and other ethnic beverages. NHANES also provides combination codes, which we used to identify when beverages had sugars added (e.g., sugar to coffee) prior to consumption. One hundred percent fruit juices included all USDA food codes with descriptions containing " $100 \%$ juice" or "orange juice", excluding juice drinks, and fruit nectars. Low/no-calorie beverages were defined as the sum of intakes of diet beverages, and tap, bottled, and flavored waters, as these beverages had low rates of consumption among the sample population. In total, 10 mutually exclusive beverage subgroups were identified. Our approach to beverage classification is consistent with the approaches of several prior studies $(11,25,26)$. A detailed list of the USDA Food Codes and corresponding descriptions comprising each beverage group is given in Appendix Table 1.

\section{Statistical Analysis}

All analyses were conducted using Stata (version 13, 2011, StataCorp, College Station, TX). Survey weights designed for the sample providing day one dietary data were used to compute simple mean intakes per person (in $\mathrm{kcal} / \mathrm{d}$ and grams/d) of total foods, total beverages, total milks, total SSBs, $100 \%$ fruit juice, total low/no-calorie beverages, and each of 10 beverage subgroups. Mean values from survey years 2009-10, and 2011-12 were 
compared to mean values from survey year 2003-04 using two-tailed $z$-tests. Mean values from survey years 2009-10 and 2011-12 were also compared using this approach. Similarly, overall mean values by group were compared, along with mean values by eating location, and source, within each group. $P$-values were corrected using Bonferroni adjustment for three comparisons, and $a<0.05$ as the threshold for statistical significance.

\section{Results}

Select demographic characteristics of the sample are presented in Table 1. Respondents were predominantly non-Hispanic White, and from households earning >185\% FPL annually. Demographic characteristics of the sample did not differ appreciably between 2003-04 and 2009-2010, between 2003-04 and 2011-12, or between 2009-10 and 2011-12.

\section{Overall trends}

Figure 1a shows mean total caloric intake, caloric intake from beverages, and caloric intake from foods by survey cycle. Per person mean total caloric intake fell by $132 \mathrm{kcal} / \mathrm{d}$ between 2003-04 and 2011-12, but trended upward (+49 kcal/d; $p>0.05)$ between $2009-10$ and 2011-12. Similarly, caloric intakes from beverages fell by $77 \mathrm{kcal} / \mathrm{d}$ between $2003-04$ and 2011-12, but beverage intake did not differ between 2009-10 and 2011-12. Over the same period, there was a non-significant decrease $(-55 \mathrm{kcal} / \mathrm{d} ; p>0.05)$ in total food intake, which trended upward between 2009-10 and 2011-12 (+53 kcal/d; $p>0.05)$.

Table 2 shows mean intake from four major beverage groups, and 10 beverage subgroups, by survey cycle among U.S. preschool children. Intake of total SSBs decreased by $57 \mathrm{kcal} / \mathrm{d}$ between 2003-04 and 2011-12. Much of this decrease was from juice drinks, which fell by $37 \mathrm{kcal}$, and soft drinks, which fell by $13 \mathrm{kcal} / \mathrm{d}$ between 2003-04 and 2011-12. There were no significant differences in total milk intake between 2003-04 and 2011-12, but intake of $>1 \%$ fat, low-sugar milk decreased by $39 \mathrm{kcal} / \mathrm{d}$. Total caloric intake from milk also trended downward between 2003-04 and 2011-12 (-21 kcal/d), but this difference was not statistically significant. Total milk intake by volume showed a similar downward trend, indicating that the shift from whole to reduced fat milk only partially attenuated this downward trend (see Appendix Table 2). Intakes of total milks, total SSBs, $100 \%$ juice, and low/no-calorie beverages did not differ between 2009-10 and 2011-12. Trends in intakes of total milks, total SSBs, $100 \%$ juice, and low/no-calorie beverages are shown in Appendix Table 2.

Figure $1 \mathrm{~b}$ shows mean caloric intake from beverages by eating location and survey cycle. In all survey cycles, the majority of beverage calories were consumed at home. Per person intake of beverage calories consumed at home fell by $73 \mathrm{kcal} / \mathrm{d}$ between $2003-04$ and 201112 , but there were no differences in beverage calories consumed at home between 2009-10 and 2011-12. There were also no significant changes in intake of beverages consumed away from home over the same period. A complete list of intakes of total foods, total beverages, and 10 major beverages by eating location and survey year are shown in Appendix Table 3.

Figure 1c shows mean caloric intake from beverages by source and survey cycle. Stores were the major source of beverage calories for all survey cycles. Between 2003-04 and 
2011-12, beverage intake from stores fell by $106 \mathrm{kcal} / \mathrm{d}$, while there were slight, but significant increases in beverages consumed from dine-in restaurants $(+7 \mathrm{kcal} / \mathrm{d})$ and all other sources $(+11 \mathrm{kcal} / \mathrm{d})$. Trends in intakes of total foods, total beverages, and 10 major beverages by source (in grams/d and kcal/d) are shown in Appendix Table 4 .

\section{Discussion}

Past studies found total energy intake from beverages among preschoolers fell between 2003-04 and 2009-10, and we extended this to 2011-12. We found that while energy intake from foods was also significantly lower in 2011/12 compared to 2003-04, the 2011-12 levels were not significantly different from 2009-10. These findings suggest much of the decline in intakes occurred between 2003-04 and 2009-10. However, we did find large, but non-significant increases in intakes of total foods and total calories between 2009-10 and 2011-12, which may suggest that caloric intake from foods among U.S. preschools may yet again be on the rise.

We also observed a sharp decrease in intakes of SSBs between 2003-04 and 2011-12, with SSB intake decreasing by $60 \mathrm{kcal}$ between 2003-04 and 2009-10 alone. While Kit, Fakhouri and Park et al. (2013) also used NHANES data, they found a smaller decrease in total SSB intake over the same period, as well as smaller mean intakes at each time in 2003-04, 2005$06,2007-08$, and 2009-10. While this difference is likely due to differences in the USDA food codes contained within the SSBs group, Kit et al. do not describe their approach in enough detail to allow for comparison of their methods with our own. Nonetheless, we followed the approaches of previous works to create our beverage groupings (25), in addition to providing a comprehensive list of the 365 USDA food codes comprising each of our beverage groupings. To our knowledge, only one other published study has supplied a similar list (11), thereby making it difficult to compare findings across studies.

In addition, recent findings showed decreases in intakes of whole-fat milks, and increases in intakes of low-fat milks, among all U.S. children (ages 2-19y) between 2001-02 and 200910 (11). Similarly, we found while there was a meaningful (>|10| kcal/d) but not statistically significant reduction in total milk, we found that intake of $>1 \%$ fat, low-sugar milk decreased between 2003-04 and 2011-12. Also, there was a meaningful but non-significant increase in intake of low-fat, low-sugar milk $(13 \mathrm{kcal} / \mathrm{d}$; +23grams $/ \mathrm{d})$ which could suggest preschoolers switched from consuming higher-fat milks, to consuming $1 \%$ or skim varieties. Notably, WIC revised its packages for children ages two and older by replacing whole milk with $2 \%$ milk in 2009 (14). We did not, however, find evidence of shifts in milk intake between 2009-10 and 2011-12, which may suggest too little time has passed for the WIC changes to have appreciably influenced milk intakes.

By eating location, there was a significant decline in beverage calories consumed at home ( $-63 \mathrm{kcal} / \mathrm{d}$ ), but no statistically significant changes in beverage calories consumed away from home. Changes in beverage calories consumed by source supported this finding, as foods/beverages consumed at home predominantly come from stores (19). Beverage calories purchased from stores decreased by $106 \mathrm{kcal} / \mathrm{d}$ between 2003-04 and 2011-12 among U.S. 
preschool children. Over the same period, there were marginal, but significant increases in beverage calories from other sources.

There are several important limitations to our study. First, we used a single 24-hour dietary recall survey to ascertain average daily intake of all foods and beverages, which may be insufficient for capturing usual intake of episodically-consumed beverages. Nonetheless, our focus here was to examine trends in intakes of key beverages such as milks, 100\% fruit juice, and sugar-sweetened beverage, which tend to be consumed by a significant proportion of U.S. preschool children (27). Other beverages such as diet drinks, sport and energy drinks, and bottled and flavored waters have lower rates of consumption (11), and thus assessment of these beverages using a single 24-hour recall may be prone to error.

The potential for reporting bias (under- or over-reporting) is another limitation. Increasing public awareness of the adverse effects of beverages on risk of child obesity could increase the likelihood of over-reporting of foods perceived as healthy, and/or under-reporting of foods perceived as unhealthy (28). For all children included in our sample, parents/ caregivers were asked to report their child's diet, which could increase the potential for intentional misreporting of the child's diet, particularly if the parent feels guilty about the healthfulness of their child's diet (29). There is, however, little evidence of this occurring in the literature.

\section{Conclusion}

Our study provides evidence the diets of U.S. preschool children changed significantly between 2003-04 and 2009-10. These changes coincide with plateauing rates of obesity among U.S. preschool children (23), which could indicate a potential link. However, while there were no significant differences, there were large increases in intakes of total calories, and calories from food between 2009-10 and 2011-12. This finding suggest that, although caloric intake from food decreased between 2003-04 and 2009-10 among U.S. preschool children, there is limited evidence that this trend may be slowing or reversing in recent years, which could be a cause for concern. By source, changes occurred primarily in foods/ beverages obtained from stores, which could be the result of changes in parent/guardian purchasing behaviors, and/or food manufacturers and/or retailer initiatives to develop healthier products and sell fewer calories. This period also encompassed important changes in the economic climate, cost of living, and food and beverage prices (30), which also may have driven changes in preschooler diets. Accordingly, further study is needed to determine which (if any) public health efforts may have contributed to these changes. Thus, while our study points to improvements in the diets of U.S. preschool children between 2003-04 and 2009-10, there is some evidence that progress may be slowing or reversing in recent years.

\section{Supplementary Material}

Refer to Web version on PubMed Central for supplementary material.

\section{Acknowledgments}

Christopher N. Ford was primarily responsible for conducting the analyses, creating tables/figures, interpreting results, and writing the manuscript. Shu Wen Ng and Barry M. Popkin provided general guidance and oversight for 
the manuscript and related analyses. Shu Wen Ng and Barry M. Popkin also provided critical review and edits to the manuscript, tables, and figures.

We thank the Robert Wood Johnson Foundation (Grants 67506, 68793, 70017, 71837) and the National Institutes of Health (R01DK098072 and CPC 5 R24 HD050924) for financial support. We also wish to thank Dr. Donna Miles for exceptional assistance with the data management and programming, Ms. Frances L. Dancy for administrative assistance, Mr. Tom Swasey for graphics support, and Dr. David Guilkey, Dr. Penny GordonLarsen, and Dr. Anna Maria Siega-Riz for assistance in this effort.

\section{References}

1. Slining MM, Popkin BM. Trends in intakes and sources of solid fats and added sugars among U.S. children and adolescents: 1994-2010. Pediatr Obes. 2013

2. Slining MM, Mathias KC, Popkin BM. Trends in Food and Beverage Sources among US Children and Adolescents: 1989-2010. J Acad Nutr Diet. 2013; 113:1683-94. [PubMed: 23916972]

3. Bolton RP, Heaton KW, Burroughs LF. The role of dietary fiber in satiety, glucose, and insulin: studies with fruit and fruit juice. Am J Clin Nutr. 1981; 34:211-17. [PubMed: 6259919]

4. DiMeglio DP, Mattes RD. Liquid versus solid carbohydrate: effects on food intake and body weight. Int J Obesity. 2000; 24:794-800.

5. Birch LL, Fisher JA. Appetite and eating behavior in children. Pediatric Clinics of North America. 1995; 42:931. [PubMed: 7610021]

6. Malik VS, Schulze MB, Hu FB. Intake of sugar-sweetened beverages and weight gain: a systematic review. The American journal of clinical nutrition. 2006; 84:274-88. [PubMed: 16895873]

7. U.S. Department of Health and Human Services. Healthy People 2020: Topics and Objectives. 2013. Nutrition and Weight Status.

8. White House Task Force on Childhood Obesity. Solving the problem of childhood obesity within a generation. 2010. Report to the President.

9. Obama, M. America's Move to Raise a Healthier Generation of Kids. 2014. Let's Move.

10. Birch LL, Fisher JO. Development of eating behaviors among children and adolescents. Pediatrics. 1998; 101:539-49. [PubMed: 12224660]

11. Mesirow MS, Welsh JA. Changing Beverage Consumption Patterns Have Resulted in Fewer Liquid Calories in the Diets of US Children: National Health and Nutrition Examination Survey 2001-2010. J Acad Nutr Diet. 2014

12. U.S. Department of Agriculture and U.S. Department of Health and Human Services. Dietary Guidelines for Americans 2010. Washington, DC: 2010.

13. IOM (institute of Medicine). Local government actions to prevent childhood obesity. Washington, DC: National Academies Press; 2009.

14. Food and Nutrition Service, U.S. Department of Agriculture. Interim Rule. Dec 6. 2007 Special Supplemental Nutrition Program for Women, Infants and Children (WIC): Revisions in the WIC Food Packages; p. 68966-9032.

15. U.S. Department of Health and Human Services, Office of Disease Prevention and Health Promotion. Healthy People 2020. Washington, DC: 2012.

16. Danyliw AD, Vatanparast H, Nikpartow N, Whiting SJ. Beverage intake patterns of Canadian children and adolescents. Public Health Nutr. 2011; 14:1961-9. [PubMed: 21729471]

17. Brownell KD, Farley T, Willett WC, Popkin BM, Chaloupka FJ, Thompson JW, et al. The public health and economic benefits of taxing sugar-sweetened beverages. N Engl J Med. 2009; 361:1599-605. [PubMed: 19759377]

18. Kit BK, Fakhouri TH, Park S, Nielsen SJ, Ogden CL. Trends in sugar-sweetened beverage consumption among youth and adults in the United States: 1999-2010. The American journal of clinical nutrition. 2013 ajcn. 057943.

19. Poti JM, Popkin BM. Trends in energy intake among US children by eating location and food source, 1977-2006. J Am Diet Assoc. 2011; 111:1156-64. [PubMed: 21802561]

20. Slining MM, Ng SW, Popkin BM. Food companies' calorie-reduction pledges to improve U.S. diet. Am J Prev Med. 2013; 44:174-84. [PubMed: 23332336] 
21. U.S. Department of Agriculture ARS, Beltsville Human Nutrition Research Center, Food Surveys Research Group (Beltsville, MD) and U.S. Department of Health and Human Services, Centers for Disease Control and Prevention, National Center for Health Statistics (Hyattsville, MD). Frequently Asked Questions. 2014. What We Eat In America, NHANES.

22. Moshfegh AJ, Rhodes DG, Baer DJ, Murayi T, Clemens JC, Rumpler WV, et al. The US Department of Agriculture Automated Multiple-Pass Method reduces bias in the collection of energy intakes. The American Journal of Clinical Nutrition. 2008; 88:324-32. [PubMed: 18689367]

23. Ogden CL, Carroll MD, Kit BK, Flegal KM. Prevalence of childhood and adult obesity in the United States, 2011-2012. JAMA. 2014; 311:806-14. [PubMed: 24570244]

24. Institute of Medicine. Accelerating progress in obesity prevention: Solving the weight of the nation. National Academies Press; 2012. Committee on Accelerating Progress in Obesity Prevention.

25. Wang YC, Bleich SN, Gortmaker SL. Increasing caloric contribution from sugar-sweetened beverages and 100\% fruit juices among US children and adolescents, 1988-2004. Pediatrics. 2008; 121:e1604-14. [PubMed: 18519465]

26. Kit BK, Fakhouri TH, Park S, Nielsen SJ, Ogden CL. Trends in sugar-sweetened beverage consumption among youth and adults in the United States: 1999-2010. Am J Clin Nutr. 2013; 98:180-8. [PubMed: 23676424]

27. Fox MK, Condon E, Briefel RR, Reidy KC, Deming DM. Food consumption patterns of young preschoolers: are they starting off on the right path? J Am Diet Assoc. 2010; 110:S52-9. [PubMed: 21092769]

28. Heitmann BL, Lissner L. Dietary underreporting by obese individuals--is it specific or nonspecific? Bmj. 1995; 311:986-89. [PubMed: 7580640]

29. Pocock M, Trivedi D, Wills W, Bunn F, Magnusson J. Parental perceptions regarding healthy behaviours for preventing overweight and obesity in young children: a systematic review of qualitative studies. Obesity Reviews. 2010; 11:338-53. [PubMed: 19780989]

30. Ng SW, Slining MM, Popkin BM. Turning point for US diets? Recessionary effects or behavioral shifts in foods purchased and consumed. Amer J Clin Nutr. 2014 


\section{What is known}

- Total energy intake among U.S. preschool children fell by $178 \mathrm{kcal} / \mathrm{d}$ between 2003-04 and 2009-10.

- Over the same period, there were decreases in total intakes of milks and sugarsweetened beverages (SSBs).

\section{What this study adds}

- This study examines beverage intake trends for total beverages, total milks, and total SSBs, as well as important beverage subgroups comprising these larger groups, among U.S. preschool children between 2003-04 and 2011-12.

- We found significant decreases in total intakes of beverages, sugar-sweetened beverages, juice drinks and caloric soft drinks between 2003-04 and 2011-12. These changes, however, primarily occurred between 2003-04 and 2009-10.

- Although there were no significant changes in intakes of total foods, and total foods and beverages trended sharply upward between 2009-10 and 2011-12. This latter finding suggests that changes between 2003-04 and 2009-10 may be reversing in recent years. 


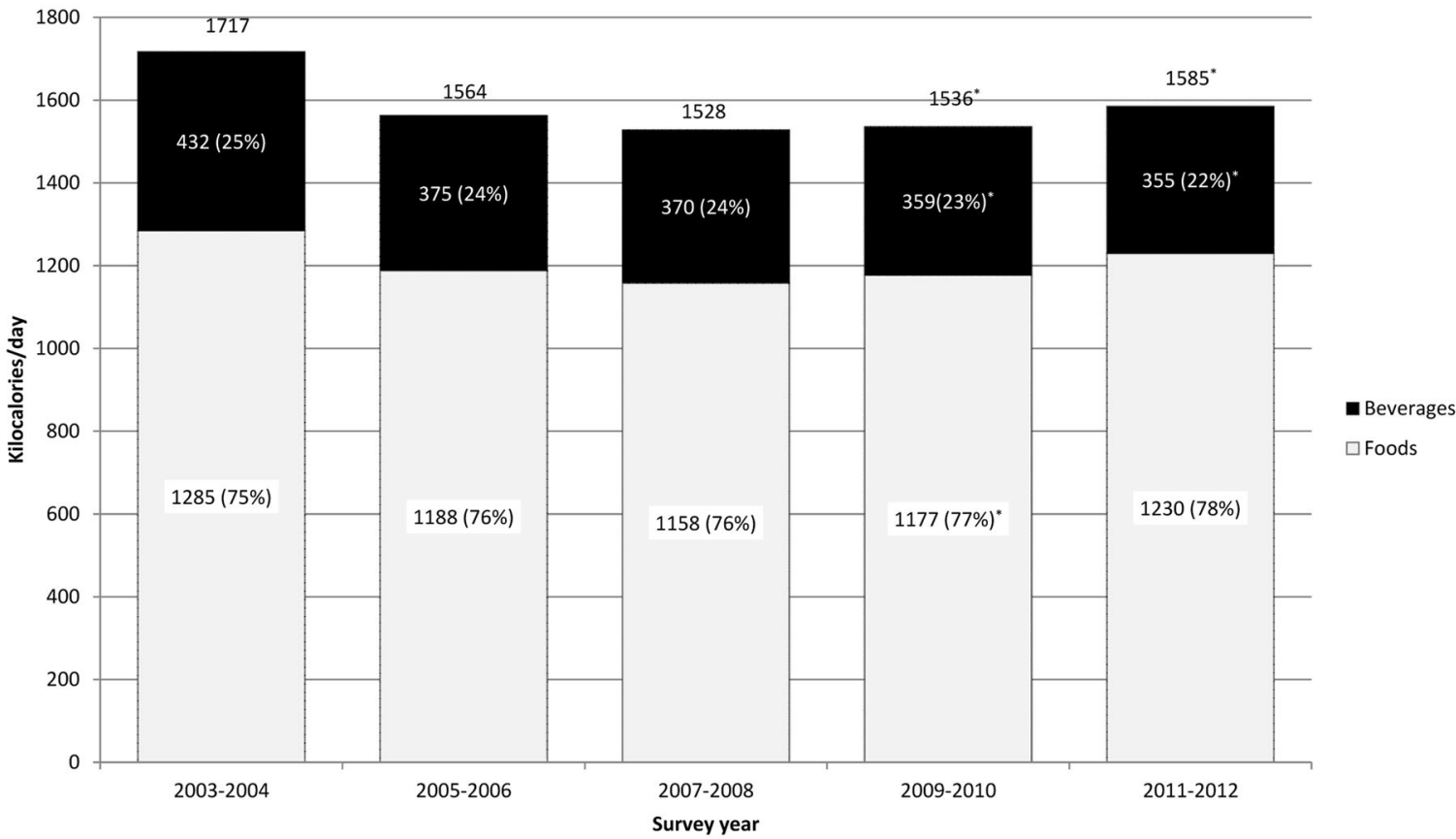

Figure 1a

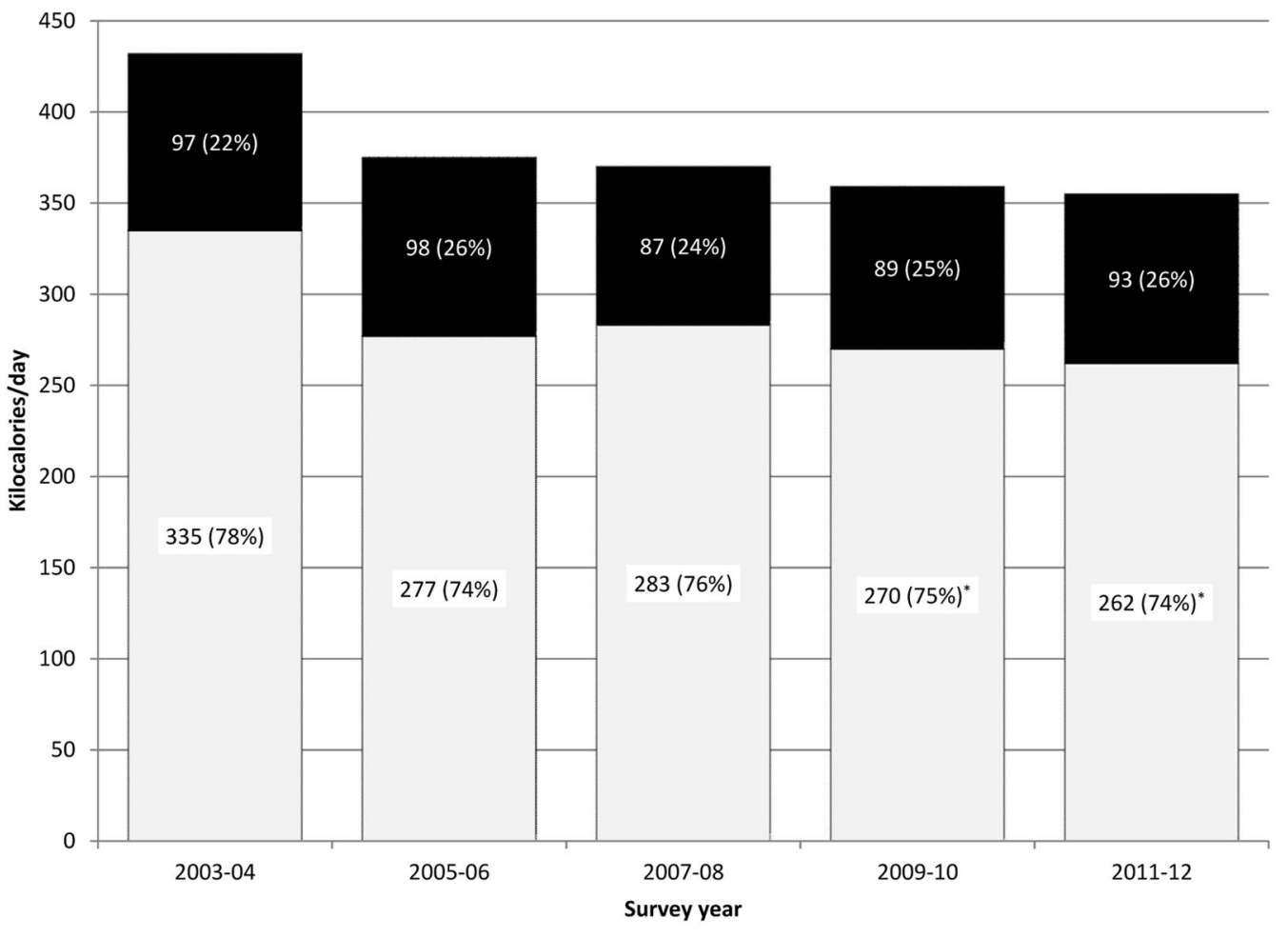

- Consumed away from home $\square$ Consumed at home

Figure $1 b$

Pediatr Obes. Author manuscript; available in PMC 2017 February 01. 


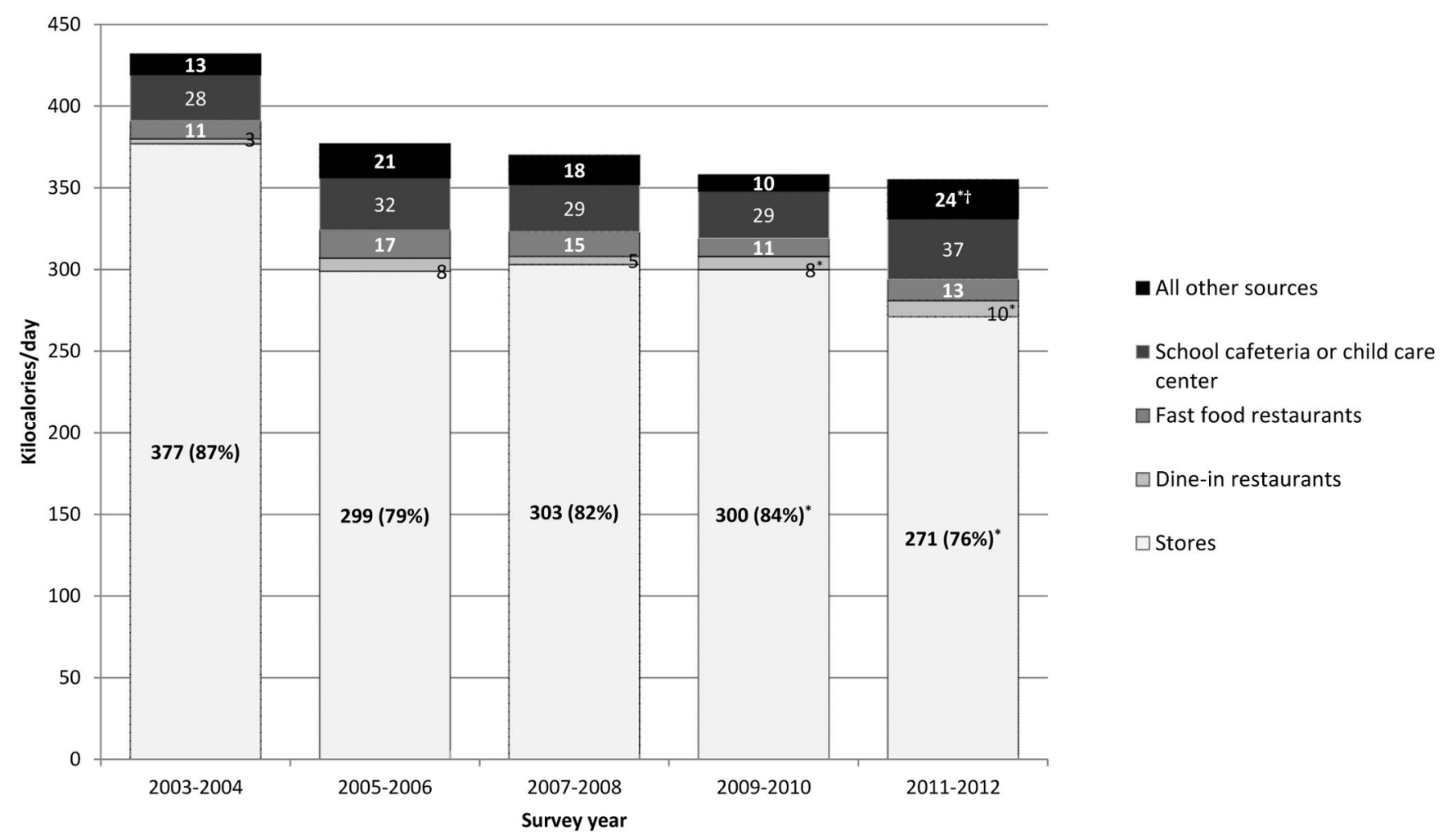

Figure 1c

Figure 1.

Figure 1a. Trends in total caloric intake from beverages, foods, and total foods and beverages ( $\mathrm{kcal} / \mathrm{d}$ ), from 2003 to 2012 among U.S. children ages 2-5y who participated in What We Eat in America's National Health and Nutrition Examination Survey during survey cycles 2003-04, 2005-06, 2007-08, 2009-10, or 2011-12.

*Value was significantly different from value in 2003-04 was significant, Bonferroniadjusted $\mathrm{p}<0.05$

$\dagger$ Value in 2011-12 was significantly different from value in 2009-10, Bonferroni-adjusted $\mathrm{p}<0.05$

Figure 1b. Trends in total beverage intake (kcal/d) by eating location (home or away) from 2003 to 2012, U.S. children ages 2-5 years among U.S. children ages 2-5 years who participated in What We Eat in America's National Health and Nutrition Survey during survey cycles 2003-04, 2005-06, 2007-08, 2009-10, 2011-12.

*Value was significantly different from value in 2003-04 was significant, Bonferroniadjusted $\mathrm{p}<0.05$

$\dagger$ Value in 2011-12 was significantly different from value in 2009-10, Bonferroni-adjusted $\mathrm{p}<0.05$

Figure 1c. Trends in total beverage intake by source (kcal/d) from 2003-04 to 2011-2012 among U.S. children ages 2-5y who participated in What We Eat in America's National Health and Nutrition Examination Survey during survey cycles 2003-04, 2005-06, 200708, 2009-10, or 2011-12. 


\begin{abstract}
*Value was significantly different from value in 2003-04 was significant, Bonferroniadjusted $\mathrm{p}<0.05$

†Value in 2011-12 was significantly different from value in 2009-10, Bonferroni-adjusted $\mathrm{p}<0.05$
\end{abstract}




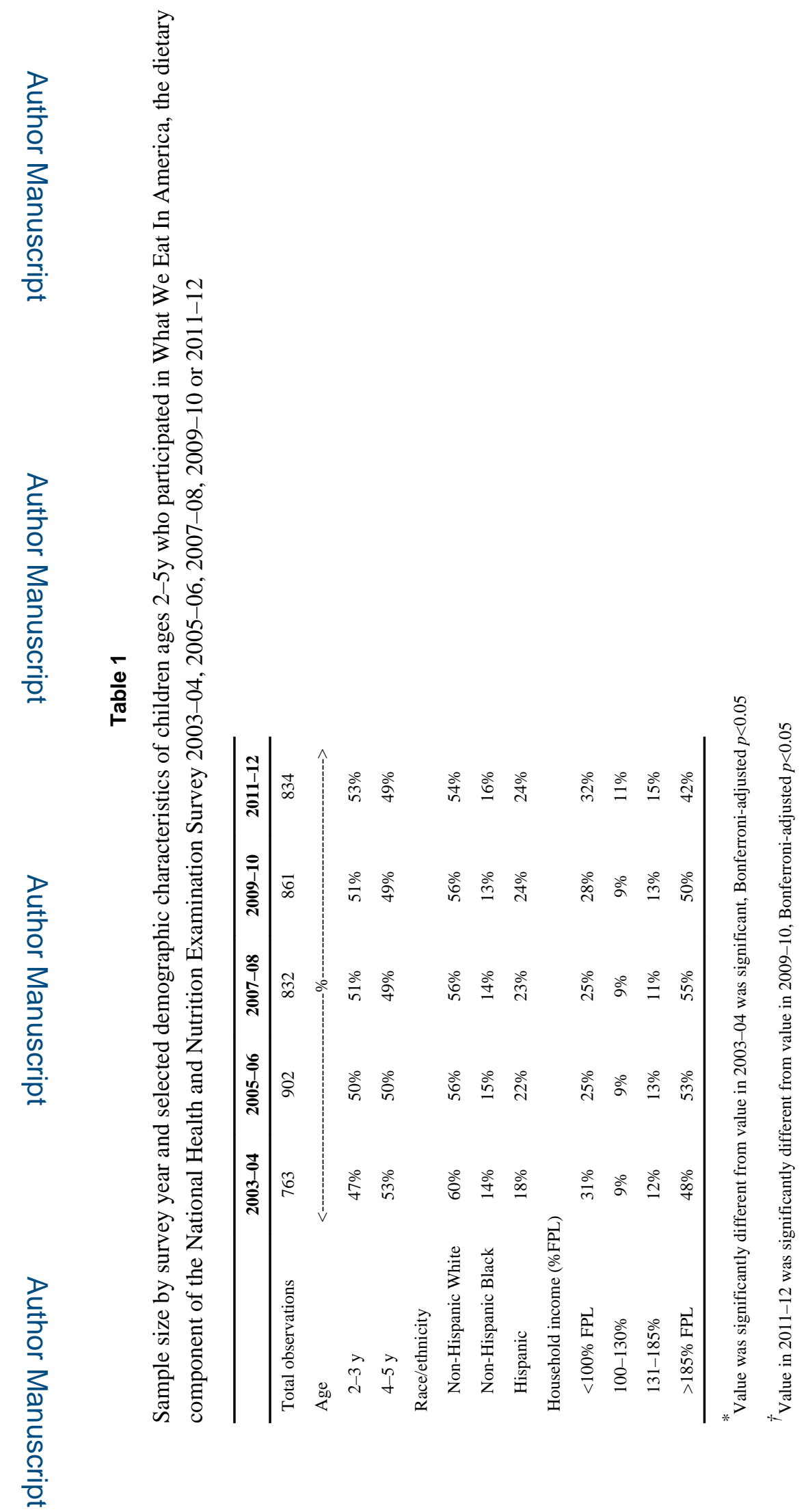

Pediatr Obes. Author manuscript; available in PMC 2017 February 01. 


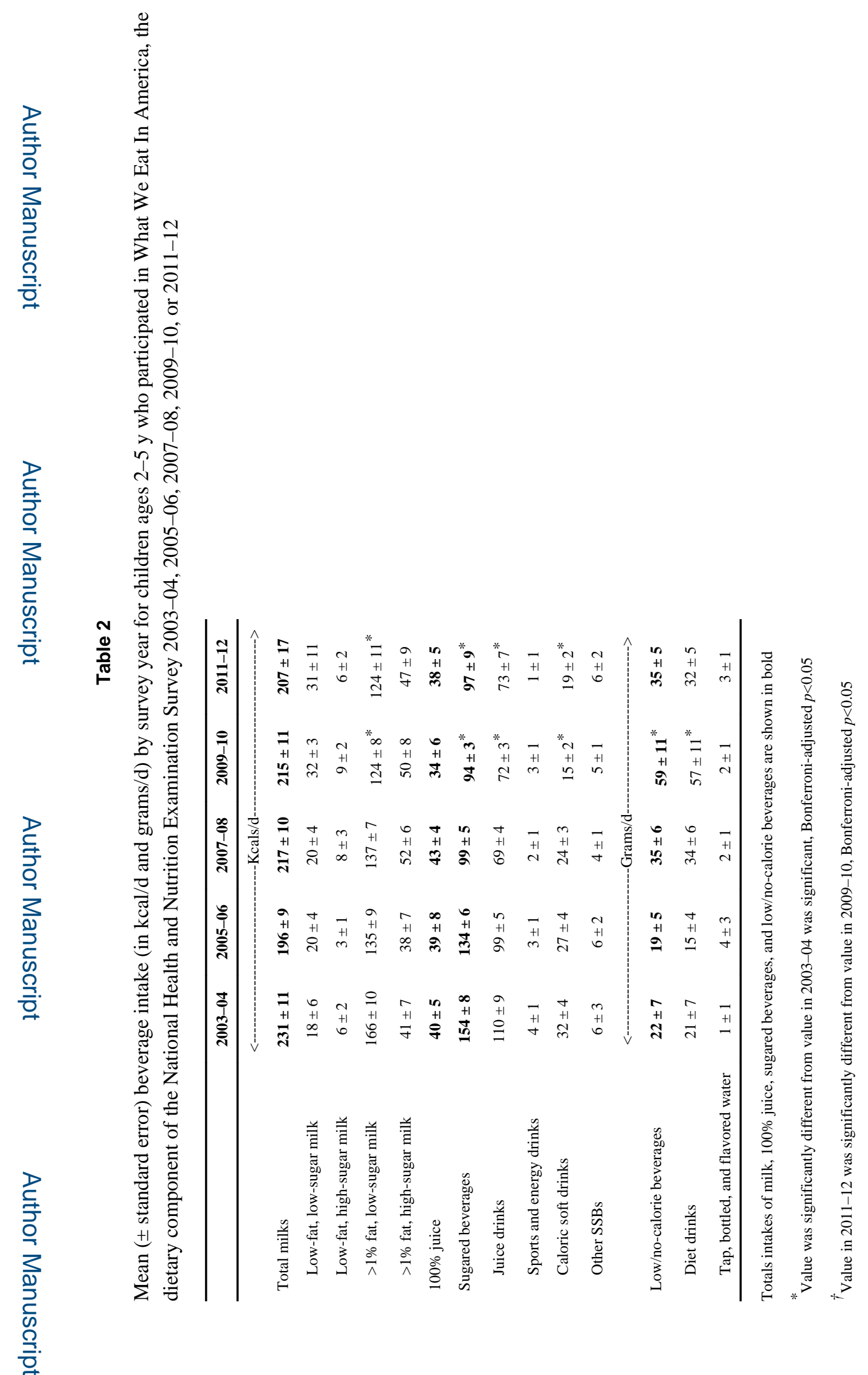

Pediatr Obes. Author manuscript; available in PMC 2017 February 01. 